\title{
Architecture and Culture: Virtuous Synergies between Agriculture and Landscape
}

\author{
Olivia Longo \\ Dicatam - Department of Civil, Architectural, Environmental, Land Planning Engineering and Mathematics - \\ University of the Studies of Brescia - Via Branze, 43 - 25123 Brescia, Italy \\ *Corresponding Author: olivia.longo@ing.unibs.it
}

Copyright (C) 2014 Horizon Research Publishing All rights reserved.

\begin{abstract}
This research was made after the preparation of a project coordinated by Marina Montuori in collaboration with Barbara Angi, Massimiliano Botti, Olivia Longo, Alessandro Muraca, Filippo Orsini, Angela Squassina. This research was based on the need to conceive an architecture taking into account the natural processes and the related anthropic mechanisms that determine the phenomenal reactions of a place. The analyzed case study has included an agricultural area in the locality Moceniga in the territory of Rosolina ( $\mathrm{RO}$ ), in the Po Delta Park. Agriculture is constantly approached to fish farming that becomes an added value as a tourist attraction. The rural landscape of Polesine is based on a complex mechanism that brings together all the environmental and productive aspects, to which add cultural aspects of the belonging context that define its specificity. The main objective of this research was to make synergistic agriculture, fish farming and landscape, allowing the latter an interesting evolution in the qualitative sense, untying agriculture and fish farming form their purely quantitative function in order to entrust them images of high aesthetic potential.
\end{abstract}

Keywords Landscape, Agriculture, Sustainable Tourism

\section{Introduction}

In this research one of the fundamental principles has been: saving resources and minimal production of pollution in all phases of the a building life cycle. Another one to integrate architecture in the environment and nature, by applying the concept of economy, understood not as the lowest cost in the short term, but as the system that allows you to avoid waste. Still another one was based on the need to build for the inhabitants welfare, which contribute to the health of the individual, of the social balance and environmental care.

According to these principles a building is not an object in itself, untied from the context, but part of an interactive and dynamic system that considers natural elements (Earth, water, etc.) and social (cultural identity) as basic materials for the project. The aim was to put in place a process of regeneration of secret plots, their dynamics, sometimes hidden, continuous transformations that animate natural and artificial. Research stands out for its low impact that comes into harmony with the environment allowing the natural order of things to remain or change according to their times and rhythms. Another key component is the man-nature relationship strengthened by an inherent unity, in which the roles of observer and observed seem invertible: the observer becomes an active part of reflexes and playing, amplified and expanded references from mirrors and water surfaces, compared to the observed object. The relationship between the building and nature is harmonized by a total integration based on the use of soft and irregular forms that put molding on the land and the space: the ground is lifted, it is thickened to become piece built. In this context of permeable elements, the system of the distances prevails that relates them evidencing architecture of the dialog and not of the juxtaposition, a new form of development of the territory that renounces to the autonomy of the architectonic fact regarding the natural element. One of the main instances is sustainability (perhaps too much abused term) that is the background to all the investigation and who inspired the idea to fully remodel the support plan of reconstructing the whole landscape architectures as limply modeled. The principles of sustainable architecture have also guided the choice of materials, their use and their construction practices that favour the use of techniques which include dry mounting, disassemblabilità and functional recovery of materials when it reaches the end of the life cycle of buildings. At last, the bound challenge to experimental and at the same time durable materials regarding the aggressiveness of the salty atmosphere: for example the use of the pultrusi (outlined in strengthened polymer, sayings also FRP) instead of the metal.

\section{The Case Study}

The research was oriented towards analysis and 
reconfiguration of an agricultural area in the locality of Moceniga in the territory of Rosolina (RO), whose municipal area includes parts of the Venetian Regional Park of the Mouth of the Po river. In this geographic area agriculture constantly is approached by the fish farming that becomes an added value like tourist attraction. The area of the municipality of Rosolina is entirely surrounded by water: with the Adige river to the North, the Po of Levante South, the Po of Brondolo West, the lagoon and the Adriatic Sea Caleri East.[1] This large amount of lagoon, river, and sea water, the ancient origins of the settlement of Rosolina witness from the route of the Roman road Via Popillia, and the prestigious legacies of many noble families that have enriched the places of valuable architectures, constitute the three main components of the structure of this territory.

The delicate and unstable balance between land and water was often subject to study and control on the part of the man who, over the centuries, has learned to live with the danger of flooding, by curbing the rivers and simplifying the hydrographic network. It is an environment shaped by the deposition of stratifications and debris from waterways, shaped over the centuries by the work of man, which has diverted the river and adjusted the water flows. The toponymy of the sites represented by Ca' Morosini, casoni (a type of farm in Veneto) of Valle Veniera and those of Valle Capitania, constitutes an added value inside these places enchanted and silent, rich of inestimable architectonic and landscaped potentialities.

The Mouth of the Po river is an ecosystem very different and very important for the survival of many animal species, especially species of birds that inhabit it, with a rate exceeding $1 \%$ of world population, the threshold for defining the areas in the literature wetlands of international importance (Grebe, Great Egret, Wigeon). Many bird species are very rare and endangered species in much of the European territory: suffice to say that during the winter the wintering populations consist of some tens of thousands of individuals. The marine areas surrounding the mouth are rich in nutrients: nitrogen and phosphorus that the Po download in the Adriatic. For this the records of fishing for Bluefish and tuna were caught right in front of the mouth. The pace of growth of many mollusks such as mussels and clams, is greatly accelerated compared to the Ionian and Tyrrhenian Sea and water is densely inhabited by a population of sea turtles.

This territory is characterized by particular environmental characteristics, vegetation and animal morphology. Is a veritable biotopical entity where mingle wrecks survivors of nature now gone, a new spontaneous appearances of plant and animal communities that contribute to the formation of a new ecosystem. The coastline of Rosolina is antecedent to the Cutting of Porto Viro (dating from around 1600) and appears as a more stable dune area, Tortuleto-Scabioseto, a rare environment, present for centuries, characterized by the presence of a typical Association of plants and lichens in the steppe and alpine environments, residues of glaciations.

In Porto Caleri, in extreme offshoot of Rosolina coast southward, are condensed in almost twenty-four hectares of beach, dunes, lagoons and depressions: what forces nature moulding and biotic elements in over four centuries, were able to build.

Surrounded by valuable environmental variety of Rosolina territory, designed by fossil dunes and bordered by the mouth of the Adige, from coastal pine forest and Botanical Garden of Porto Caleri, the study area is located between the Sega Valley, the lagoon of Caleri and the Capitania Valley, its perimeter is marked by street of the Valleys and the street Moceniga.

The area is about 10 acres and was created following the jobs of reclamation of the old Moceniga Valley. In the South of the area there is a small degraded church, erected by the Venetian Mocenigo family in 1789, dedicated to the Blessed Virgin of conception. In the North, along the street of the Valleys, there is a wooded area of about 4.5 hectares planted with species typical of the area.

Its landscape marks the memory of visitors through its indefinite and permanent land-water relationship, hence a high aesthetic quality given by the reflection of the architectural shapes and long horizontal skyline of trees, typical of the ancient coastal cordons of dunes, which is due to the combined action of wind, rivers and the sea. Of the seven existing sand dunes in Polesine, four involve the territory of Rosolina: the oldest, dating back to pre-Etruscan period, is located in the northwestern part of the territory. The economy of these places is linked to two main activities: fishing and agriculture. Most of the area of the Po Delta is characterized by Islands, so-called because inclusive among the river branches that constitute the delta system and the Adriatic sea. Almost the whole territory lies below sea level (between -2 and -4 metres). The hydrographic network is further complicated by artificial canals dealt or dug below the surface of the floor. The conquest of the territory was obtained by reclamation that, until the advent of the industrial revolution, used technologies based only on canalizations that exploited also the slighter natural slopes of the ground, making to flow out for gravity the inside waters toward mirrors of valley or directly toward the sea. This system has often been undermined by heavy rainfall and tides of exceptional importance that, when added to river routes, have also led to the destruction of land reclamation and water have returned to the lands that the man had laboriously earned. Since the 19th century, this painful cohabitation between man and the environment has been mitigated by the invention of an instrument of extraordinary effectiveness against the waters: the scooping plant. This new system has allowed to lift and to also estrange from the grounds the low waters, that is those that would not be poured again for natural fall in the rivers. The unnatural drainage of the marshy zones, already very depressed, it has provoked a further lowering of the ground (subsidence) up to a maximum value of over $200 \mathrm{~mm}$ the year.

Observing and metabolizing the traditional activities, that have been being taken place for centuries in the whole territory of the area of study, their complexity and their 
possible interpretations, a plan of the area Moceniga has been done, that could include both the history, the culture and the traditions, and the innovations and the future necessities of the buyers and the consumers.

The general objectives included:

The reconfiguration of the area in general maintain the original features, both cultural and environmental;

- The location of innovative features and the reorganization of existing ones;

- The integration of new activities with existing natural resources;

- The creation of new synergies that generate dynamic alternative economic processes related to sustainable tourism.

\section{The Landscape}

The rural landscape of the Polesine founds him, therefore, on a complex mechanism that gathers in itself all the environmental and productive aspects, proper of which cultural aspects are added the context of affiliation that they define the specificity of it. It constitutes an important element of interconnection among the natural system and that man-made, in which the ability of the man to influence the territory is expounded with different formality that has to extend to situations of equilibrium however.

Inside this articulated system, the principal objective of the research has been that to make synergistic agriculture, fish-farming and landscape, allowing this last an interesting evolution in qualitative sense, purely untying the agriculture and the fish-farming from their quantitative function in order to give to their images an elevated aesthetical potentialities.

Local agriculture is notable both for the dimensions and for the quality of the crops: among those annual they prevail the maize, the wheat and the sugar beet; among those multi-year they have a principal role the medical grass, the poplar, some kinds of fruit trees, the sunflower and the chicory. The physiognomy of the crops depends in direct way both from the cultivated kinds that from those infesting. It deals with kind arrived by two areas well you define: in ancient times from the Mesopotamia zone; in more recent times, after the discovery of America, from the area Central America. In the seasonal crops there is a strong incidence of enough specialized infesting vegetation: in the spring period the poppies, the fiordaliso and the spergularia are found above all; during the summer, the autumn and the winter the amarantis and the chenopodis are predominant.[2]

The poplars, constituted by American hybrid poplars, are often found in areas floodplain, subject to floods during the floods: it is this, in fact, the only cultivation able to bear such environmental conditions.

In this case, the agrarian-lagoon landscape becomes a sort of common denominator able to check and to manage the territorial transformations, not only guaranteeing a profitable production of material goods, but also of those immaterial universally recognized, as the cultural identities and the ecological qualifications

The greatest transformation operated by the man is the agrarian landscape: the greatest parts of the surfaces of the Earth have suffered the imprint of the architect-farmer that has built new landscapes to survive. The productive landscape is the result of the orographic conditions, water, climatic and of the finalities of the cultivation; the operations of the farmer assume a rational and economic logic of necessity.

The saving in the gestures and in the work, the pursuit of the product optimal damage forms place constant. The agrarian landscape is a common figurative world, resulted of conditionings and shared finality.

The rural landscape is a complex mechanism that gathers in itself all the environmental and productive aspects, proper of which cultural aspects are added the context of affiliation that they define the specificity of it. It constitutes an important element of interconnection among the natural system and that man-made one, in which the ability of the man to influence the territory is expounded with different formality that has to extend to situations of equilibrium however.

The cultural values that identify a homogeneous rural system are tied up not only to the different types of cultivation and production, but also to the craftsmanship and the kitchen, to the architectural and constructive techniques and of control and environmental management.

Inside this articulated system, the principal objective of the process of modification of the territory can be that to make synergic agriculture and landscape. This action would allow an interesting evolution of the landscape in qualitative sense, purely untying the agriculture from its quantitative function to submit her a tied up image to the quality.

The landscape, and in prevailing way the agrarian landscape, would become so a sort of common denominator able to check and to manage the territorial transformations, not only guaranteeing a profitable production of material goods, but also of those immaterial universally recognized, as the cultural identities and the ecological qualifications.

Uncertain, mobile, open to the change is the delta territory, where river, sea and Earth are composed in different forms, they interact among them and with the intentions and the projects of the so many actors that in the time they have leaned out on this scenery. To the mobility the continuous research of contexts of sense is contrasted, of territorial structures, of delimitations that want to be firm, solid, sure: the so many strategies of government of the territory, are them politics, administrative, economic, social that have decomposed now, now re-aggregate the territory. Inevitably this wish of consolidation clashes with the mobility and the uncertainty of the environmental and natural dynamics that the results of the actions and the equilibriums make unpredictable that will be gone to re-configure of time in time.

You think, for instance, to the matter of the delimitation of the Park of the Mouth of the Po and the search of a limit or a system of limits that it cut out the Park from the not-park. In 
the various proposals, the delimitation has modified more times its configuration, widening and tightening the area of the natural Mouth to protect, up to the definition of the attached paper to the law where the Park limits it to follow the streets of the water, the different river branches, understanding some clippings of the valleys excluding others of it. A Park that is not range emerges on the contrary "marginal", that is marked by the sea borders, river and lagoon but, above all, from the sections of these borders.

The lagoon landscape, constituted by porous and indefinite limits between earth and water, as functional manufactured article it has always been built for arresting the effects of the aggressions of the natural events that, of epoch in epoch, they put to risk uses, constructions and traditions. The lagoon natural scenery as precarious equilibrium can be interpreted among two typologies of landscape: that of the continuous imperceptible changes of relationships between earth and water and that of the invasions of the sea against which the man builds works of defense as banks and edges.

This design research on the landscape of Moceniga could be imagined as the to weave of two systems and of two rhythms: the first based on the construction of the void, a capillary system of interpreted places and expressed as waiting, of wise interventions that across least interventions restore relationships and maintain the slow movement of men, waters and forms from which this territory draws life improves; the other, more evident in the section of ground and fast in the fruition, reinterpret figures and techniques of the construction of the lagoon landscape of the valley as banks and excavations, to elaborate an infrastructure thorn that welcomes and mitigates the tectonic plenum of the most massive functions.

On the base of these reflections, the project of the park is the fruit of a patient search contemplated to the constitution of an only integrated system, in which the functional program succeeds in pacifically cohabiting with the delicate metabolism of the natural trials.

The select approach pursues the logic of a "naturalism without form" where the creation of the compositional system, the choice of the constructive methods and the approach of the materials have the common objective of to develop an architecture that answers to the parameters of the sustainable planning to limit the more possible the environmental impact.

\section{The Theme of the Border}

The Card n. 8 of the Picture of environmental Restoration of the Municipality of Rosolina, sets at the base of this study, it foresees some interventions for touristic valorization of the area of Moceniga: the construction of receptive structures, commercial, of support to the net of runs that the near Park of the Delta (Mouth) has built for the discovery of this part of the territory of the Polesine to make possible. The Card also foresees the flood of a vast area to the purpose to reconstruct a landscape of pre-reclamation. The new valley Moceniga would owe so to become a place of the memory: not more a structure with eminently productive finality but a testimony of the traditions of the valley.

The intervention owes therefore to depart from the definition of a basin of water in which is possible to develop the activities of breeding and care of the fish preparing the new colauro, the fish farms and the channel of edge. The thousand of meters earth's cubes, the result of the decision to dig, is not brought elsewhere but they remains in the area and they determine partly the general sketch of it. In fact, it is not more ethically acceptable (and economically sustainable) to move great quantities of material, which would involve an environmental impact and anachronistic costs. Earth is so used for modeling parts of the landscape to build banks and perimeters, to make the buildings visually irrelevant and dissimulated in the new lines of horizon, to screen from the traffic vehicular parts of the intervention that cannot put aside from the road layouts but that from these they must be protected.

The dominant component of the whole new configuration geometrically is not an imposed perimeter but a border from the mutable profile, usual character in the fixed scene of Polesine. A long border that edges the new valley and that it becomes, of time in time, composite receptive structure, museum and center of study, equipments and services for the sport (figure 1).

The theme priority declined is therefore that of the bank (understood as border), peculiar present three-dimensional element constantly in the landscape of Polesine. The border is system of containment that defines forms and it is tied up to the man-made of a landscape studded by few signs: isolated low buildings and of modest dimensions, the layouts of the cultivated fields, the tangle of the fish farmers and the channels. The relationship earth-water has been made for centuries artificial by the job of the man and is tied up to the necessities to optimize the resources of the places to draw maintenance from hunting, fishing and agriculture.

The theme of the border, as in the ample Park of the Delta of the Po, it seems to also return dominant to this small staircase, structuring the whole strategy of formation of the new Park Moceniga.

The border or edge, are a compositional theme very investigated, it is a concept that physically postpones to a multiplicity of situations that they are in nearness to something of recognizable that has a border, a perceivable limit. Edges and borders are, for instance, the areas of proximity of an urban center, those prepared along an infrastructure of transport or along a course of water. They often coincide with the many artificial of the man-made and with the elements of citizenship that delimit areas and situations as the road that it surrounds a district, the rows of trees that circumscribe a cultivated field the path that coasts along a wood. 


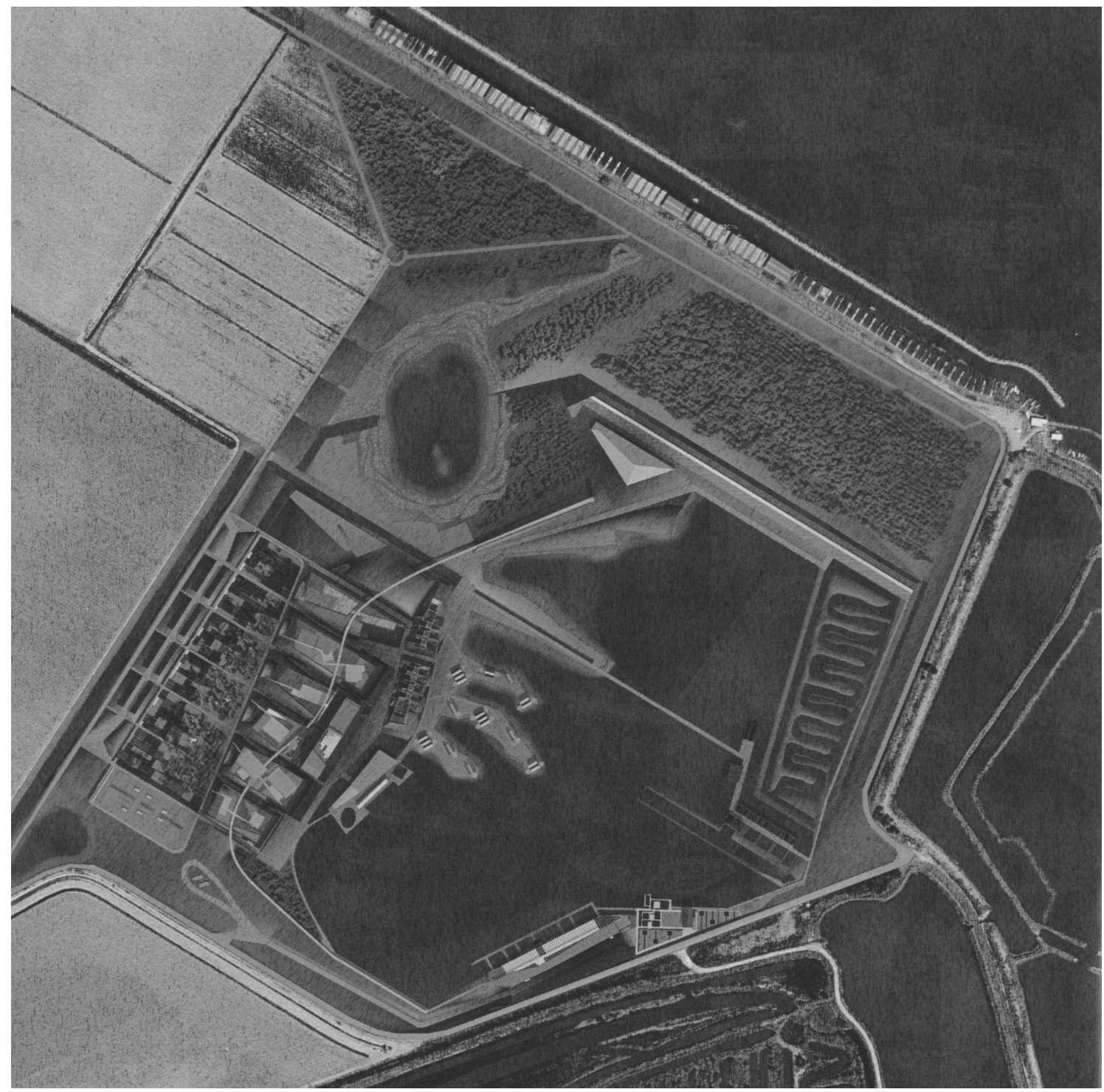

Figure 1. Master plan of New Valley Moceniga.

In the continuity geomorphology of the territory, the edge and the border correspond to middle situations among contexts with different densities and morphologies or with different uses of the ground and different partitions of the landscape. They coincide with residual situations of a territorial system man-made, studded by episodes installed you and by occasions that they attend to be able to transform the existing one to vary some settlement question.

In many cases these are casual situations, resulted of actions whose confinements and limits have not kept in mind of what it remained. Of other song the border is that line that follows the term of a territorial unity both disposition how conventional as, for instance, that of a valley or of a state; but also that of the administration of a territory, of the ownership of a single subject, of the destination of use of an area; in general of the juridical-administrative state of a territory, of a resource, of a good. Also the limit is a line of separation among two situations, it becomes the defensive rampart, the road or the path that it circumscribes a district, the bank that delimits a basin of water or a river that delineates the confinements of the neighboring territories.

In our case, the border also postpones to specific actions as that to erect a wall, to set poster and to build banks. They are fit that when they are translated in buildings they delimit an edge that purchases the material thickness of a built perimeter, whose meant it is permeated, also in the dimensions, from the relationships of proximity with the bordering realities.

The construction of the border follows a logic of design very checked but the native genesis is tied up to characters of spontaneity and repeatability, being so strongly tied up and, at the same time, guaranteed by the presence of natural agents.

The level of control is measured continually with the search of clarity in the definition of the limits and at the halves to which the architectural and landscape project is constantly turned: parts harder, others softer and more mobile, even more others taller or ampler and wider draw the 
low skyline of the edge of the basin for the valley fishing.

The search sets the accent on the complicated plot of the containers of a different water, from sweet to salty, deeper, with tones of color always different, a water that assumes various forms: the great basin of the valley, the fish farms of winter, the eddies, the lake of repopulation, the basin of compensation, the channels, or still the swimming pools dug in the wood plate stretched out on the mirror of the valley.

The border always drawn and artificial it now becomes bank beach, barena or hard edge giving form to the contained liquid. Water is mutable subject and is here protagonist of this study: it puckers under the action of the wind or it turns into foam in the passages of level, it solidifies with the winter cold up to turn into plate of ice, it exhibits chromatic variations under the sun or in it absence, in the dark or in the weak light of the moon, it produces vapors that are lost in the fog, it reflects and it doubles the objects and the surrounding nature. Water is material inconstant that ends never to practice its own charm.

\section{The Valley Fishing and the Area of the Museum}

The observation of the life of the valley fishing can happen only through the proximity with the systems that regulate its operation. The activities of fishing are organized around the valleys fishing, mirrors of brackish water, delimited by embankments, in communication with the open sea or with the lagoons through culverts, destined to the fish activity. The arrangement of these valleys and the operations that follow in the various periods of the year are practically been intact in the centuries, done hi the only due variations to the employment of new materials. The working cycle begins to end February with the montà or rather migration of the fish, especially of small ransom, from the sea in the valley, through the culverts, whose bulkheads have opportunely opened with a more elevated level of water in comparison to the lagoon, so that the consequent tide, created by the outflow, irresistibly attracts the fishes. The operations of montà continue to the first of May. In some cases however, because of the lowering of the ground, the level of the water in the valley can be inferior to that of the lagoon (also when there is low tide) for which the montà is not feasible. You can resorts then to the semena, that consists in the novellame captured by the experienced pescenovellantis (fishermen) in the shores of the Adriatic and subsequently freed in the pond previous acclimatization of some months in a kind of tub embanked said serajo. In the summer period the fish eats micro fauna, algae and mollusks that it finds in abundance in the pastures of the valley. The temperature and salinity of the water is constantly checked (so also in winter) so that the increase or diminution of mottos values is not cause of pestilence of the fish population. The vallesans (fishermen), because of secular experience, performs regular renovations of the salty water, or they introduce that sweet, according to the breakers, exploiting the phenomenon of the tides or through the scooping.

At the end of the summer the level of the fishing pond is kept low, to favor the influx of water of lagoon through the sewer maistra (principal), this it favors the smontà of the fish that, once more, it is instinctively suited to go up again the tide along the channels of vegnùa to earn the open sea. Between sea and sewer maistra is mediate the colauro, ample wide channel around 15-20 meters and long from 50 to 100 meters, where particular devices are predisposed for the capture of the fish. At first the cogolere, obstructions prepared to acute angle, stop it preventing the escape of it in sea or the return in the valley, subsequently, the labyrinths of the lavorieri with so much of compartments (camarele for the fish; otele for the bisati or eels) they allow the selection of it in base the dimensions. The samples that aren't mature will be addressed in the tubs of the valley fishing, said of risalvo, where they will be protected and fed for the winter period. The fit fish to the sale will be fished with the volega (fords), selected, composed in the cassettes and envoy to the market or loaded directly in the refrigerator trucks, or it will be secret in big wood baskets told vieri set in the water to maintain it alive and to be able to withdraw it to the necessity.[3]

Traditionally in the valleys white fish is raised, correspondent to five kinds of mullets: bosega, mecia, otregan, caustelo and verzelata. They also raise orate, basses and eels. This activity of fishing has called fraima (the etymology is uncertain, perhaps from the Latin infra hiemes, under the winter). It has beginning to end September / first of October, and it continues to Christmas, with continuous and nonstop maneuvers of influx and outflow of salty water, bringing to the capture of big part of the fauna of the valley. Then, actually to end January, it is still fished but with rhythms and very limited captures. Finally, from end March to the last new moon of April, the remained bisati are fished. [4]

In the oriental part of the area, in correspondence of the building constituted by the small church of the Moceniga, a museum has been inserted thought not as a whole building but as a system of fit objects about to represent the various components of the place.

At the museum it has been attached a center studies to university level to deepen the history of the material culture of the places and the systems of operation of the valleys fishing.

The museum of the material culture and the center studies embody the concept of border translating it in built forms. The buildings have been conceived in proximity of the small church erected by the family Mocenigo, that - after the demolition of the near cason of valley - it has remained for long time only mute witness of the presence of the man.

The proximity has involved some radical choices, to the purpose to avoid, as far as possible, that the lack of a condition of absolute physical and symbolic predominance on the places from the small oratory meant the intolerable intervention of an aggressive modernity that these areas have also experimented. 


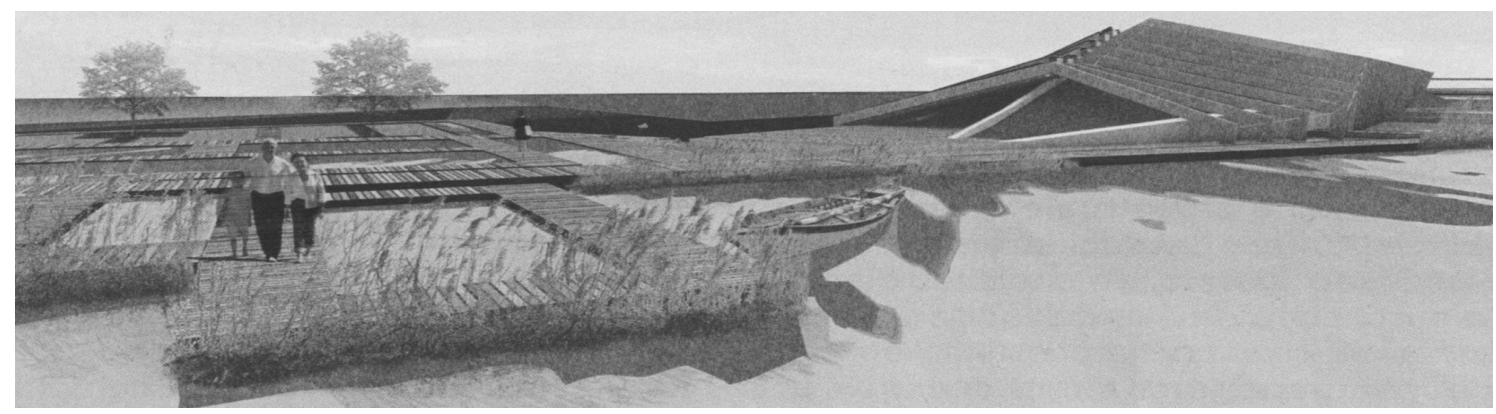

Figure 2. Museum of the material culture.

The dimension of the museum, in harmony with the prescriptions of the Card n. 8 of the Picture of environmental Restoration of the City Hall of Rosolina, have involved a configuration of the section of the building, structured in form of bank, whose summit doesn't overcome the height of the existing church $(+5.20$ meters on the level of the sea).

A long bank adequately in degree to place side by side the historian and stately building without producing conflict or embezzlement. The museum, to the shelter of this bank, it decidedly goes down under the plan of country structuring itself on two levels and comparing itself with the landscape and the water of the new valley, offering to the sights in field along the usual image, in the memory, of a tilted edge and green that announces, and it becomes, a geographical fact.

The operated dig articulates in a sort of fissure of access, sets around four meters below the plan on which the church rises. From this excavation there is the access of the museum (figure 2) and you can arrive, thanks to a great stairway, at the level of the church.

The artificial bank is constituted by a sequence of portals performed with the technique of the pultrusione: box outline, realized with polymers, prefabricated and climbed on to dry, very light and resistant to traction.

These characteristics, which are proper of the construction steel, in the profile pultruso reach binding limits, which bring to a great facility of assemblage, to a sensitive saving in the cost of the transports, to an increased durability especially in relationship to the brackish environment.

Under to the portals, whose profile molt constantly crossing in longitudinal sense the complex, of the simple volumes - a sort of box in the box - they entertain the in demand functions.

The vocation cultural pole that offers a double front, green toward the hinterland, immaterial toward the valley (the portals dip them in the water that comes to lick up the inside volumes, situated perceptively in second floor thanks to the quickly sequence of the brought shades), includes also the ideal reconstruction of the cason of valley. In place of a philological recovery the project resorts to the evocation of the ancient building. The imprint of the disappeared building is engraved in the terrestrial one thanks to a system of tubs and thin lines of water, that return the geometry of the building changing it in a sort of labyrinth of runs and liquid fragments, integrated also it in the circuit that encircles the valley, heralding of a multiplicity of discoveries and unexpected episodes.

\section{The Sustainable Tourism and the Pole Receptive}

According to the ethical codes of the sustainability, codes that can be undersigned and embraced by the tourism of territory, tourist activity must not become a factor of the depletion of the proposed areas as destinations of the trip, but it can come to represent for the single destinations an important tool to reach a durable economic and social development instead.

The tourism, together with the agriculture and to the fish farm, it is among the principal economic resources of this territory, therefore the search has deepened the various themes keeping in mind of the matters of the sustainable tourism exposed in the European Paper [5] of which it is object, and following line-drives and the principles turned to a type of congruent tourism with the places in the respect of the environment and the cultural resources of them.

Although an approved definition universally of echo-tourism or responsible tourism both still to come, it is possible to underline some elements key in almost all the interpretations of this expression: respect and safeguard of the environment and particularly of the ecosystem and of the biodiversity, with minimal environmental impact of the structures and the tied up activities to the tourism; respect and safeguard of the traditional culture of the local populations; requisite of informed consent from such populations on the activities it undertook to tourist purpose; where possible, active share of the local populations in the management of the echo-tourist enterprises; sharing with them of the consequential partner-economic benefits from the tourism.

The responsible tourism is an approach to the tourism born at the end of the eighties and it is characterized from a double worry both for the environment of the places visited by the tourist that for the comfort of the populations that live there. In literature and in the media a lot of variations of the denomination responsible tourism are used for substantially referring to the same concept. It sometimes speaks for example of sustainable (with reference to the economic concept of sustainable development) tourism, solidarity tourism (with reference to the equitable commerce and 
solidarity or to the initiatives of solidarity toward the Third World), aware (with reference to the aware consumption) tourism and street saying. Of none of these expressions a rigorous definition universally exists recognized. The Italian Association for the Responsible (AITR) Tourism has adopted in 2005 the following definition: "the responsible tourism is the tourism affected according to the principle of social and economic justice and in the full respect of the environment and the cultures."

The tourism of territory is a form of tourism characterized by the direct knowledge of the people and the different aspects of the identity of a place, offered in their general and contemporary dimension, inside a different experience of trip from the usual tourist schemes.

The western sector of the area has been destined to the reception of the receptive system characterized by four types of tourist offer for as many different types of use: campground, services and covered parking lot, a compact hotel, with swimming pools and cafe restaurant and a diffused one contained residences inside a sort of bank dressed again of green. To these buildings they are added about ten bungalow attested on a sort of barene. The net of the drive runs, cycle-pedestrian, pedestrian, it is connective element and to the meantime functional tool to the progressive revealing of the new spatial complexity.

The territory (that is the place visited with its artistic riches, landscape, natural, human, etc.) it represents an opportunity to explore according to the different levels of interest of the tourist and a possibility to have an authentic contact with different styles of life from the proper ones, living experiences of knowledge it lavishes from the aesthetical, intellectual or emotional point of view.

The compact hotel is a building in line on two floors. The presence of usual typological elements (the spaces of reception, the services, the offices, etc.) it is integrated by functional endowments that should bring the area of the hall of the hotel to act from public space, around which the shops and the cafe gravitate, to service of the compact structure as of the other two anticipated receptive typologies from the project. The coverage of the building, treated to green, it is integrated as form and geometry with the modeling of the surrounding territory, shaping itself as a hanging garden for the clients of the hotel, a sort of scenic place in privileged position.

Using the cubage destined by the Card to the residential structures they have been anticipated a series of constructions to team in shape of bank that as annex of the compact structure can be used. These can also be rented for longer periods of a normal room of hotel, granting a great privacy and allowing to be closed in the periods of irregular use.

The concept to separate the types of use, both for quality and for quantity it allows in fact to realize economies of management and to limit the energetic consumptions, as well as to avoid the aggression of the environment in case of missed use.

The diffused hotel is constituted by about ten receptive unity distributed long artificial barene behind the valley fishing, in an environment suspended between earth and water. The concept of the versatility is totally one of the themes hinge of these small transformable buildings, so that to be able so much to be exploited as in the summer period in that winter. Maintained the principles of compactness of the building, the introduction of elements of furnish modular transformable and multi-functional allows the building to have two different configurations, diurnal and nighttime.

A solar greenhouse, endowed with flowing fixtures with big windows and prepared southwest, it helps in the winter period the energetic efficiency of the building acting from accumulator of heat, while in the summer it turns it into porch.

The search considers the possibility to use a new model of leisure time: "to re-discover the nature", as Aldo Cibic sustains, taking to reference the so-called ones "the pensioners' gardens" that exist in Europe, positioned on the urban borders to the outskirts of the cities. The job on Moceniga focuses on an inhabited rural park in which a simulation is produced to tell a history and to show different possible sceneries.

The challenge doesn't consist only of succeeding in defining all that that happens during the year to change of the seasons and of the meteorological conditions, but also in to understand the reasons in base to which the people often invest time and resources in forms of diversion packaged neglecting very interesting and less expensive alternative opportunity.

\section{Conclusions}

This approach induces to a planning type conceptual that offers certain autonomy in comparison to the quality of the construction and to the coherence of the results, beyond whatever admissible variation. The relationship between planning and maintenance is so guaranteed from the evolutionary possibilities of the project same that pursues the objective of the convertibility for every component of it, and of functional character and type constructive. To such end, the search of sustainable materials, of new typological solutions and of innovative constructive languages a strategy of great importance is revealed for the institution of a trial compatible design with the surrounding environment and with the continuous transformations of the economic dynamics of the echo-tourism.

The search is set therefore the objective to diversify the receptive offer, so that to guarantee an efficient economic mechanism in relationship to the different expectations, age and economic availability of the tourists that reach the Delta of the Po during the period of the vacations, not only in summer. Variable flow transform the landscape during the months painting the coasts during the warm season and then in winter, return to the beaches and uniform appearance of the characteristic territories bordering the Eastern Veneto.

The concept of variability of landscapes in relation to 
functional demands and seasons can become a leitmotif for the conception of buildings that can be completely closed and sealed, during periods of non-use, becoming a sort of work of land art, like Eduardo Chillida had been called to do an installation along the embankment and the edges of the valley fishing.

The advantages of a similar proposal are manifold and they go from an effective rationalization of the necessary resources for the operation of the whole receptive structure, to the possibility to differentiate the offer in base of the period of time taken in examination, putting in scene a continuous passage of landscapes.

\section{REFERENCES}

[1] Cf. Flumina Associazione guide turistiche autorizzate del Polesine. Rosolina. Polesine Eventi Supplemento 2010; Anno VI: 22-3.

[2] Cf. Sburlino G. La vegetazione delle valli da pesca della provincia di Venezia. in AA.VV. Le Valli da pesca del comprensorio veneziano dal Tagliamento al Brenta 1994. And Cf. Grossele R. Atlante del territorio costiero, lagunare e vallivo del Delta del Po.

[3] Cf. Zanetti M. La valle da pesca lagunare: caratteri strutturali e funzionali. In Caniato G, Turri E, Zanetti M. La laguna di Venezia 1995: 299-309.

[4] Cf. Rallo G. Guida alla natura nella laguna di Venezia Itinerari, storia e informazioni naturalistiche 1996.

[5] La carta europea per il Turismo sostenibile nelle aree protette1992. 